\title{
Intestinal Calcium Absorption in
}

\section{Exogenous Hypercortisonism}

\section{ROLE OF 25-HYDROXYVITAMIN D AND CORTICOSTEROID DOSE}

\author{
Robert G. Klein, Sara B. Arnaud, J. C. Gallagher, Hector F. Deluca, \\ and B. LAWRENCE RigGS \\ From the Endocrinology Research and Gastroenterology Units, Department of Medicine, Mayo \\ Clinic and Mayo Foundation, Rochester, Minnesota 55901, and the Department of Biochemistry, \\ University of Wisconsin School of Agriculture, Madison, Wisconsin 53706
}

\begin{abstract}
A B S T R A C T Pharmacologic doses of corticosteroids impair intestinal calcium absorption and contribute to negative calcium balance. However, the relationship between the impaired calcium absorption and a possible defect in the conversion of vitamin $D$ to its physiologically active form, 1,25-dihydroxyvitamin $D$, is unknown. We compared fractional calcium absorption (double-isotope method, 100-mg carrier) and serum 25hydroxyvitamin D (25-OH-D) (Haddad method) in 27 patients receiving pharmacologic doses of prednisone with 27 age-, sex-, and season-matched normal subjects. In patients receiving high daily doses of prednisone $(15-100 \mathrm{mg} /$ day $)$, calcium absorption $(P<0.02)$ and serum 25-OH-D $(P<0.001)$ were decreased. However, in patients receiving low doses $(8-10 \mathrm{mg} /$ day) or high doses (30-100 $\mathrm{mg}$ ) of prednisone on an alternate-day schedule, both of these parameters were normal. Calcium absorption in the patients treated with daily prednisone correlated inversely with the dose of corticosteroids $(r=-0.52, P<0.025)$ and, in all steroid-treated patients, correlated directly with serum 25-OH-D $(r=0.58, P<0.01)$. In four patients who received high-dose corticosteroid therapy for an average of $4 \mathrm{wk}$, serum 25-OH-D decreased by $35.5 \%$ from pretreatment values. Administration of a physiologic or near-physiologic dose of synthetic 1,25-dihydroxyvitamin $D_{3}(0.4 \mu \mathrm{g}$ daily for 7 days) to patients receiving high-dose corticosteroids led to an increase in calcium absorption in all patients. These results suggest that calcium malabsorption in the cortico-
\end{abstract}

Dr. Klein's present address is Sansum Medical Clinic, Santa Barbara, Calif. 93102. Address reprint requests to Dr. Riggs at the Mayo Clinic.

Received for publication 11 October 1976 and in revised form 12 January 1977. steroid-treated patients is due to a dose-related abnormality of vitamin $\mathrm{D}$ metabolism and not to a direct effect of corticosteroids on depressing transmucosal intestinal absorption of calcium.

\section{INTRODUCTION}

Pharmacologic doses of corticosteroids impair intestinal absorption of calcium (1-11) and result in a negative calcium balance $(4,9-11)$, which may contribute to the development of osteoporosis. It has been postulated that corticosteroids decrease intestinal calcium absorption either by interfering with the metabolic activation of vitamin $\mathrm{D}$ or by antagonizing, directly or indirectly, the effects of vitamin $D$ on the gut, or by both mechanisms (12). Conversion of vitamin $\mathrm{D}$ to its physiologically active form, 1,25$(\mathrm{OH})_{2} \mathrm{D}_{3},{ }^{1}$ requires hepatic 25 -hydroxylation followed by renal $1-\alpha$-hydroxylation (13). Corticosteroid treatment potentially could interfere with either of the two successive hydroxylations or with other metabolic pathways of vitamin $D$, or it could antagonize the effect of vitamin $D$ on intestinal calcium transport.

Avioli et al. (14) reported that prednisone administration to normal man reduced the plasma half-life of injected $\left[{ }^{3} \mathrm{H}\right]$ vitamin $\mathrm{D}$. They found an abnormal silicic acid chromatographic profile of plasma extracts, suggesting decreased conversion of vitamin $\mathrm{D}$ to biologically active plasma metabolites. However, Aloia et al. (15), in using a competitive binding assay, found that serum 25 -hydroxyvitamin D (25-OH-D) was normal in a group of patients with Cushing's syndrome and with iatrogenic hypercortisonism. Also, studies

${ }^{1}$ Abbreviations used in this paper: $1,25(\mathrm{OH})_{2} \mathrm{D}_{3}, 1,25$-dihydroxyvitamin $\mathrm{D}_{3}$; 25-OH-D, 25-hydroxyvitamin $\mathrm{D}$. 
in rats $(3,5,6,8,16)$ demonstrated a direct effect of very large doses of corticosteroid on transmucosal calcium transport that was independent of vitamin $\mathrm{D}$ metabolism. However, other studies in rats by Carré et al. (17) suggested that corticosteroids may affect vitamin D metabolism by inactivating $1,25(\mathrm{OH})_{2} \mathrm{D}_{3}$ after intestinal localization. Thus, the relationship of impaired calcium absorption to vitamin D metabolism in hypercortisonism is unclear.

Studies attempting to relate the defect in calcium absorption to vitamin D metabolism have not been reported. Therefore, we evaluated intestinal absorption of radiocalcium, serum 25-OH-D, and corticosteroid dose in 27 patients receiving pharmacologic doses of prednisone for a variety of connective tissue disorders and in 27 age-, sex-, and season-matched normal subjects. In a small number of patients, we determined the effect of small doses of $1,25(\mathrm{OH})_{2} \mathrm{D}_{3}$ on calcium absorption to observe the responsivity of the intestine to the physiologically active metabolite of vitamin D. Our results suggest that calcium malabsorption in the steroid-treated patients is due to abnormality in vitamin $\mathrm{D}$ metabolism, the degree of which is proportional to the dose of administered steroid.

\section{METHODS}

Patients. The 27 patients undergoing radiocalcium absorption studies had a variety of connective tissue disorders (Table I), for which they had received pharmacologic doses of corticosteroids for periods ranging from 1 mo to $15 \mathrm{yr}$ (average $3 \mathrm{mo}$ ). Three experimental groups (high-dose, alternate-day, and low-dose prednisone) and a control group were studied. 16 patients were receiving high-dose prednisone therapy (mean dose $40 \mathrm{mg} /$ day, range 15-100 mg/day). Six patients were receiving prednisone as a single dose on alternate days (mean dose $68 \mathrm{mg}$ every other day, range $30-100 \mathrm{mg}$ every other day). Five patients were receiving

TABLE I

Underlying Connective Tissue Disease in Prednisone-Treated Patients

\begin{tabular}{cccc}
\hline & \multicolumn{3}{c}{ Type of treatment } \\
\cline { 2 - 4 } Disease & $\begin{array}{l}\text { High } \\
\text { dose }\end{array}$ & $\begin{array}{c}\text { Alternate } \\
\text { day }\end{array}$ & $\begin{array}{c}\text { Low } \\
\text { dose }\end{array}$ \\
\hline
\end{tabular}

Temporal arteritis

Polymyositis

Obstructive pulmonary disease

Rheumatoid arthritis

Lupus erythematosus

Polymyalgia rheumatica

Polyarteritis nodosa

Mixed connective tissue disease

Total no. of patients

$\begin{array}{lll}6 & 1 & 2 \\ 1 & 2 & \\ 2 & 2 & \\ 1 & & 2 \\ 1 & & 1 \\ 1 & & \\ 2 & 1 & \\ 2 & & \\ 6 & 6 & 5\end{array}$

low-dose prednisone therapy (mean $9.5 \mathrm{mg} /$ day, range 8-10 $\mathrm{mg} /$ day). All except one of the patients were studied at a time when their underlying disease was suppressed and when their condition was stable as judged clinically and by laboratory indices. Criteria for inclusion in the study included normal serum glutamic-oxaloacetic transaminase, alkaline phosphatase, and creatinine values, absence of previous stomach or small bowel surgery, and no prior treatment with sex steroids, calcium, or vitamin D. Antacids were stopped at least $24 \mathrm{~h}$ before each study. No patient had evidence of osteoporosis at the time of the study. 27 control subjects were selected with the same criteria. Age and sex of these subjects were similar to those of the corticosteroid-treated patients. Patients and controls were studied between the end of April and October to minimize the effects of seasonal variations on serum 25-OH-D and calcium absorption. Complete dietary histories were obtained by a trained dietician from all normal and corticosteroid-treated subjects. Additionally, four patients - two with temporal arteritis, one with rheumatoid arthritis, and one with polymyalgia rheumaticahad serum drawn for 25-OH-D determination before and after 3-7 wk of treatment with high doses of prednisone (mean $45 \mathrm{mg} /$ day, range $15-100 \mathrm{mg} /$ day). Informed consent was obtained in all patients and control subjects before the study.

Laboratory studies. A double-isotope method was used to assess intestinal calcium absorption. The fraction of a radiocalcium dose absorbed at the end of the 6-h test period was calculated by computer with the use of a mathematical deconvolution method as previously described $(18,19)$. All studies were performed in the fasting state between 8:00 and 9:00 a.m. No food was allowed for the first $4 \mathrm{~h}$ of the study, at the end of which time a low-calcium lunch was given. Patients receiving prednisone were not given their usual morning dose on the day of study until the noon meal. Three of the patients receiving alternate-day prednisone were tested on their "on" day and three on their "off" day.

A dose of $10 \mu \mathrm{Ci}$ of high specific activity ${ }^{47} \mathrm{Ca}$ (Atomic Energy Commission, Oak Ridge, Tenn.) was given by mouth with $100 \mathrm{mg}$ of calcium (as calcium chloride) carrier in 200 $\mathrm{ml}$ of deionized water. $5 \mathrm{~min}$ after the oral calcium drink, $10 \mu \mathrm{Ci}$ of sterile, pyrogen-free ${ }^{45} \mathrm{Ca}$ was injected intravenously. Heparinized blood samples were serially obtained on $10 \mathrm{oc}-$ casions over the $6-\mathrm{h}$ period of the test. $4 \mathrm{ml}$ of plasma was counted for ${ }^{47} \mathrm{Ca}$ in a standard well-type gamma counter (1185 Searle Automatic, Searle Analytic Inc., Des Plaines, Ill.) using a single-channel pulse-height analyzer to exclude counts from the daughter isotope ${ }^{47} \mathrm{Sc}$. For determination of ${ }^{45} \mathrm{Ca}$ radioactivity, $2 \mathrm{ml}$ of plasma was placed in scintillation solution (Instagel, Packard Instrument Co., Downers Grove, Ill.), and beta emissions were counted in a scintillation counter (Isocap 300, Searle Analytic Inc.) after waiting a minimum of $8 \mathrm{wk}$ for decay of ${ }^{47} \mathrm{Ca}$ and ${ }^{47} \mathrm{Sc}$. All counts were corrected for quenching and for ${ }^{45} \mathrm{Ca}$ contamination of the oral ${ }^{47} \mathrm{Ca}$ preparation.

Serum calcium and magnesium were measured by atomic absorption spectrometry. Serum creatinine, alkaline phosphatase, and phosphorus were measured by standard AutoAnalyzer techniques (Technicon Instruments Corp., Tarrytown, N. Y.).

Serum 25-OH-D was measured by a modification (20) of the competitive protein-binding assay of Haddad and Chyu (21). Preparation of the serum differed. Methanol/chloroform (2:1) was used for extraction of lipids (22). This extract was chromatographed on a Sephadex LH20 column of $0.9 \times 20$ cm (Pharmacia Fine Chemicals, Div. of Pharmacia, Inc., Piscataway, N. J.) in chloroform/hexane (1:1), and the 25OH-D component was isolated (23). Fractions containing 25- 
OH-D were evaporated to dryness under nitrogen and redissolved in $95 \%$ ethanol for assay. The competitive binding assay uses a rachitic rat renal cytosol as a binding protein. Competition for binding of labeled $25-\mathrm{OH}-\mathrm{D}_{3}$ by unlabeled 25-OH- $\mathrm{D}_{2}$ and $25-\mathrm{OH}-\mathrm{D}_{3}$ is equivalent in this assay system. The coefficient of interassay variation calculated for the current study was $9.6 \%$.

Administration of $1,25(\mathrm{OH})_{2} D_{3}$. The short-term effect of a 7-day administration of $0.4 \mu \mathrm{g} /$ day of synthetic $1,25(\mathrm{OH})_{2} \mathrm{D}_{3}$ (Roche Diagnostics Div., Hoffmann-LaRoche, Inc., Nutley, N. J.) on calcium absorption was studied in five normal subjects and in five of the patients receiving high-dose corticosteroid therapy. The studies were conducted on a metabolic ward. During these studies the patients ingested their usual diets with respect to calories, calcium, phosphorus, and vitamin D. Serum and urine calcium determinations were made daily during $1,25(\mathrm{OH})_{2} \mathrm{D}_{3}$ administration. Calcium absorption tests were performed before and after the 7-day treatment period; no $1,25(\mathrm{OH})_{2} \mathrm{D}_{3}$ was administered the morning of the second test.

\section{RESULTS}

The clinical characteristics, results of dietary histories, and biochemical data of the patients and control subjects are summarized in Table II. There were no significant differences in age, sex, or dietary history, or in serum minerals (calcium, phosphorus, magnesium) or alkaline phosphatase.

Serum 25-OH-D. Individual concentrations of serum 25-OH-D were within the range of normal (7$50 \mathrm{ng} / \mathrm{ml}$ ) in all except one patient, whose value was $6.5 \mathrm{ng} / \mathrm{ml}$. Mean values, however, were significantly $(P<0.001)$ lower in the high-dose corti- costeroid group than in the control group. Mean values for the low-dose and alternate-day groups did not differ from those of the control group (Table II). In both groups of patients receiving daily prednisone, serum 25-OH-D correlated inversely with the dose of the drug $(r=-0.52, P<0.025)$ (Fig. $1 a)$ and directly with fractional calcium absorption $(r=0.58, P<0.01)$ (Fig. 2). There was no relationship between calcium absorption and serum 25-OH-D in the 27 normal subjects or between calcium absorption and the estimated intake of vitamin $D$, serum minerals, or alkaline phosphatase in either normal or corticosteroidtreated patients.

Fig. $1 b$ illustrates the effect of treatment of 15-100 mg of prednisone daily on serum 25-OH-D in four patients treated for an average of $4 \mathrm{wk}$ during the summer. The average decrease in serum 25-OH-D was $37 \%$ for this small group. The magnitude of change and the corresponding daily dose of prednisone are as follows: $15 \mathrm{mg}$ was followed by a $24.5 \%$ decrease, $30 \mathrm{mg}$ by $39 \%, 45 \mathrm{mg}$ by $34 \%$, and $100 \mathrm{mg}$ by $44.6 \%$. The proportional decrease in each of these values was significantly more $(P<0.01)$ than changes expected as a result of interassay variation.

Calcium absorption studies. Values for fractional calcium absorption for the corticosteroid-treated and normal subjects are given in Table II, and individual values are given in Fig. 3. In neither the normal subjects nor the corticosteroid-treated patients, was there a significant correlation with fractional calcium

TABLE II

Clinical, Dietary, Biochemical, and Calcium Absorption Data in 27 Patients and 27 Normal Subjects

\begin{tabular}{|c|c|c|c|c|}
\hline & \multicolumn{4}{|c|}{ Study group } \\
\hline \multicolumn{5}{|l|}{ Prednisone dose, $m g$ (mean } \\
\hline Age, $y r$ & $55.5 \pm 3.2$ & $48.0 \pm 8.1$ & $57.1 \pm 3.2$ & $52.3 \pm 7.9$ \\
\hline \multicolumn{5}{|l|}{ Diet } \\
\hline Vitamin D, U/day & $215 \pm 35$ & $142 \pm 62$ & $189 \pm 31$ & $303 \pm 76$ \\
\hline Calcium, mg/day & $994 \pm 116$ & $652 \pm 216$ & $839 \pm 109$ & $1,154 \pm 224$ \\
\hline \multicolumn{5}{|l|}{ Serum biochemical data } \\
\hline Calcium, $m g / d l$ & $9.31 \pm 0.09$ & $9.50 \pm 0.21$ & $9.31 \pm 0.07$ & $9.43 \pm 0.13$ \\
\hline Phosphorus, $m g / d l$ & $3.48 \pm 0.04$ & $3.52 \pm 0.15$ & $3.68 \pm 0.18$ & $3.20 \pm 0.14$ \\
\hline Magnesium, $m g / d l$ & $1.98 \pm 0.01$ & $2.00 \pm 0.05$ & $2.00 \pm 0.05$ & $2.03 \pm 0.03$ \\
\hline
\end{tabular}

All values are mean $\pm \mathrm{SE}$ except for serum $25-\mathrm{OH}-\mathrm{D}$, for which mean and range are given.

* Significance of difference from normal group: $P<0.001$.

\# Significance of difference from normal group: $P<0.02$. 

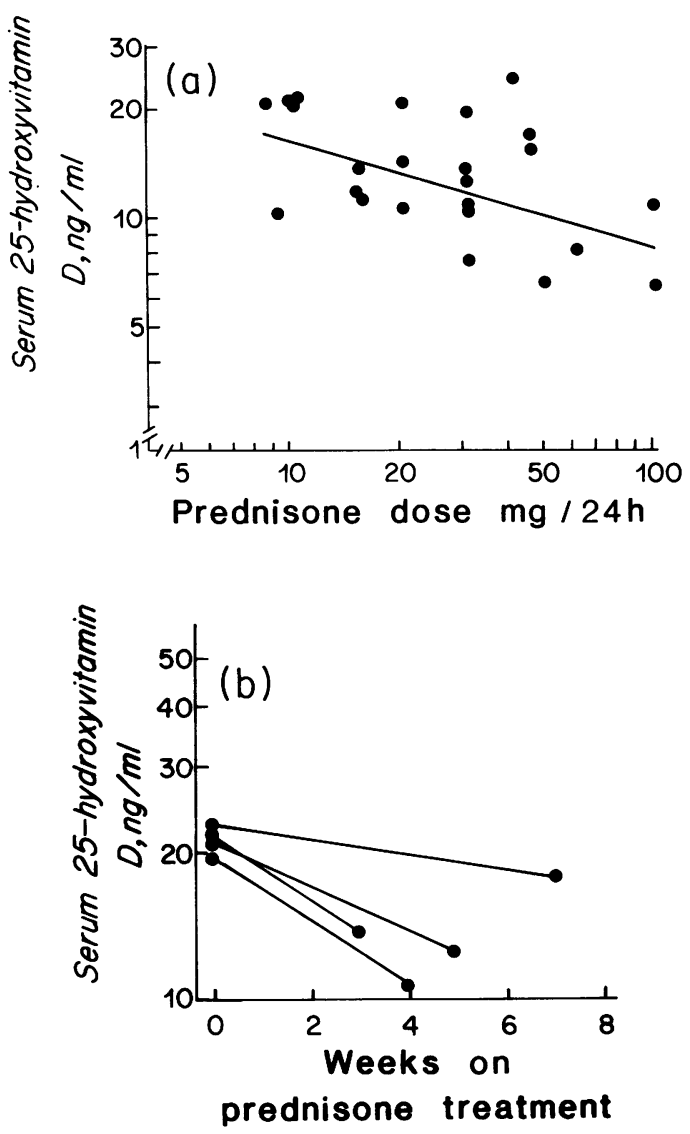

FIGURE 1 (a) Relationship of daily dose of prednisone $(8-100 \mathrm{mg})$ to concentration of serum 25-OH-D. Regression is logarithmic and significant $(r=-0.52, P<0.025)$. (b) Effect of daily doses of $15-100 \mathrm{mg}$ prednisone on serum 25OH-D measured before and 3-7 wk after initiation of treatment.

absorption and estimated habitual dietary intake of calcium. Mean values for calcium absorption were within the normal range in the low-dose and alternate-day groups but were significantly lower $(P<0.02)$ in the high-dose group of corticosteroid patients than in the control group or other treatment groups. In four of the patients who were receiving high-dose, daily prednisone, values for fractional calcium absorption were in the high-normal range. The diets of these four patients did not differ from those of other highdose, steroid-treated patients or normal controls. However, they were suntanned and had been exposed to 2 or $3 \mathrm{~h}$ of midafternoon sunshine daily. An additional three suntanned patients in the high-dose group had significantly decreased fractional calcium absorption values and correspondingly lower concentrations of serum 25-OH-D.

Effect of $1,25(\mathrm{OH})_{2} D_{3}$ administration. The mean variation of calcium absorption in replicate weekly studies in five normal subjects was $4.8 \%$. As shown in
Fig. 4, administration of $0.4 \mu \mathrm{g} /$ day of synthetic 1,25 $(\mathrm{OH})_{2} \mathrm{D}_{3}$ resulted in an increased calcium absorption in four of five normal individuals and in all five of the corticosteroid-treated patients. Both the difference in calcium absorption before and after treatment and the posttreatment values were greater in the corticosteroid-treated group (Fig. 4) than in controls.

Treatment with $1,25(\mathrm{OH})_{2} \mathrm{D}_{3}$ resulted in hypercalciuria, i.e. more than $300 \mathrm{mg}$ calcium/day, in one normal subject, who excreted $277 \mathrm{mg} / 24 \mathrm{~h}$ before 1,25$(\mathrm{OH})_{2} \mathrm{D}_{3}$ treatment and $345 \mathrm{mg} / 24 \mathrm{~h}$ after. After 1,25 $(\mathrm{OH})_{2} \mathrm{D}_{3}$ administration to the five normal subjects, the mean urine calcium increased from $209 \pm 20.6$ to $234 \pm 32.6 \mathrm{mg} / 24 \mathrm{~h}$; this increase was not significant. In the corticosteroid-treated patients, the mean urine calcium increased significantly after $1,25(\mathrm{OH})_{2} \mathrm{D}_{3}$ administration, from $163 \pm 40$ to $197 \pm 32 \mathrm{mg} / 24 \mathrm{~h}$ ( $P$ $<0.05$ ). Serum calcium did not change significantly in either group.

\section{DISCUSSION}

Our data show that the decrease in intestinal absorption of calcium associated with high-dose corticosteroid administration is accompanied by decreased concentration of serum 25-OH-D. The latter could be due to nutritional deficiency of vitamin $D$ or to an effect of corticosteroid therapy on vitamin D metabolism, by decreasing either the absorption of vitamin $\mathrm{D}$ or the reabsorption of metabolites involved in a recently described enterohepatic circulation of 25-OH-D (24). However, these explanations are not supported by clinical or biochemical findings. All patients had adequate amounts of vitamin D in their diets, and they were studied during the summer months when nutritional status of vitamin D generally is best (25). None of the patients had evidence of steatorrhea or the concentrations of blood minerals or alkaline phosphatase that are found in nutritional deficiency disease. In the four patients studied before and

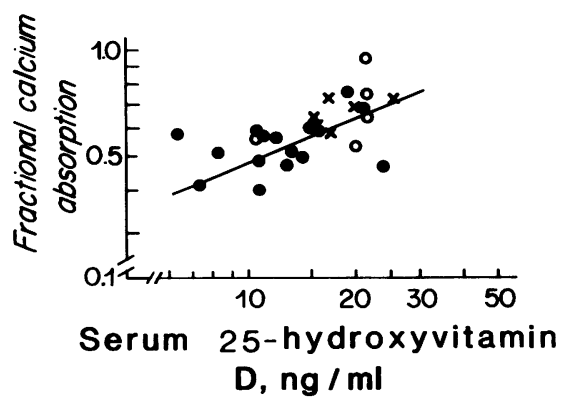

FIGURE 2 Relationship between fractional intestinal absorption of calcium, calculated at $6 \mathrm{~h}$, and serum 25-OH-D. Regression is logarithmic and significant $(r=0.58, P<0.01)$. $\checkmark$, high-dose corticosteroid patients; $O$, low-dose patients; $\times$, alternate-day patients. 


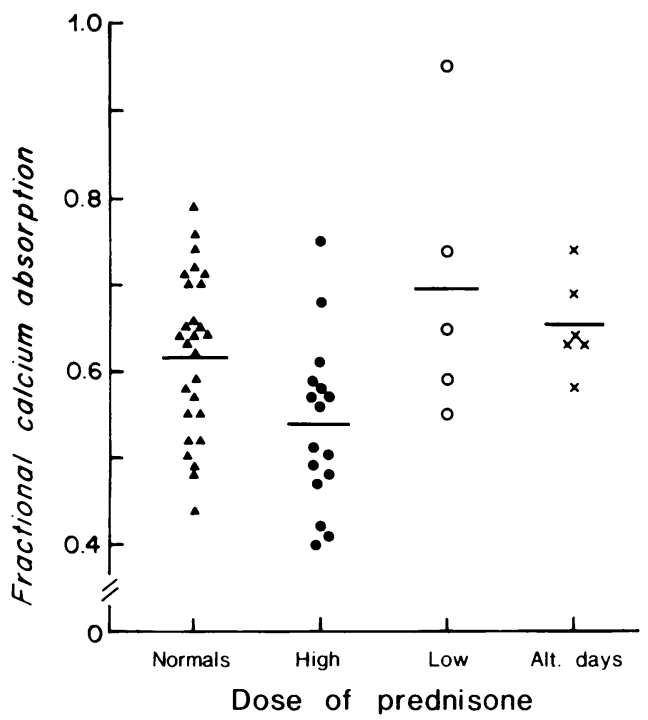

FIgURE 3 Individual values for fractional intestinal absorption of calcium, calculated at $6 \mathrm{~h}$. $\Delta$, normal individuals; ○, high-dose corticosteroid patients; $O$, low-dose patients; $\times$, alternate-day patients. Mean for high-dose group is significantly lower than that for normals.

after 3-7 wk of therapy with high doses of corticosteroids, serum $25-\mathrm{OH}-\mathrm{D}$ decreased by $35.5 \%$. It is unlikely that depletion of vitamin D stores could have occurred in such a short time. Also, a specific effect on vitamin $D$ metabolism is suggested by the inverse correlation between corticosteroid dose and serum 25-OH-D.

Gallagher et al. (4) have reported that small doses of vitamin $D$ were ineffective and that large pharmacologic doses (mean dose $250 \mu \mathrm{g} /$ day) ${ }^{2}$ were required to correct calcium malabsorption in hypercortisonism. By contrast, we found that calcium malabsorption was reversed by $0.4 \mu \mathrm{g} /$ day of synthetic $1,25(\mathrm{OH})_{2} \mathrm{D}_{3}$, an extremely small dose. Based on information presently available (26-28), this probably is a physiologic or near-physiologic dose. Thus, impaired conversion of vitamin $\mathrm{D}$ to $1,25(\mathrm{OH})_{2} \mathrm{D}_{3}$ is suggested.

Additionally, correction of calcium malabsorption in our patients with a physiologic or near-physiologic dose of synthetic $1,25(\mathrm{OH})_{2} \mathrm{D}_{3}$ is strong evidence against a specific corticosteroid-induced defect in transmucosal calcium transport that is unrelated to vitamin $\mathrm{D}$ metabolism. Such an abnormality has been reported to be present in corticosteroid-treated rats $(3,5,6,8,16)$. However, this species is particularly resistant to developing corticosteroid-induced osteoporosis (29), and doses of corticosteroids required to demonstrate this effect were in the order of $5 \mathrm{mg} / \mathrm{kg}$ larger than those encountered under clinical circumstances in man.

\footnotetext{
${ }^{2}$ Equivalent to $20,000 \mathrm{IU}$.
}

The metabolic pathway of vitamin D metabolism which is impaired concerns the intermediary metabolite of vitamin D, 25-OH-D. It is not clear whether the decrease in serum 25-OH-D which we have observed reflects decreased hepatic 25-hydroxylation of vitamin $\mathrm{D}$ or, as has been shown to occur after chronic therapy with anticonvulsant drugs $(30,31)$, a more rapid degradation and metabolism of 25-OH-D to biologically inactive forms. It is of interest that both glucocorticoids and anticonvulsant drugs are known to induce drug- and steroid-metabolizing microsomal enzymes $(32,33)$. However, the data do not exclude the possibility of an additional abnormality in subsequent metabolism of 25-OH-D such as decreased renal 1- $\alpha$-hydroxylation or accelerated inactivation of $1,25(\mathrm{OH})_{2} \mathrm{D}_{3}(17,34)$.

Previously, it has been reported in renal transplant recipients that calcium absorption was inversely related to corticosteroid dose, independent of the degree of renal function (35). Our observation that neither small daily doses of prednisone $(<15 \mathrm{mg} /$ day) nor large doses given on an alternate-day schedule decreased calcium absorption or lowered serum 25-OH-D is of practical clinical importance. The latter observation may explain in part why less negative calcium balance data were reported on an alternate-day schedule of medication (36). Also, the normal concentrations of serum 25-OH-D reported by Aloia et al. (15) could be reconciled with our findings if some of their patients were receiving the equivalent of $<15$ $\mathrm{mg} /$ day of prednisone or were receiving corticosteroids on an alternate-day schedule.

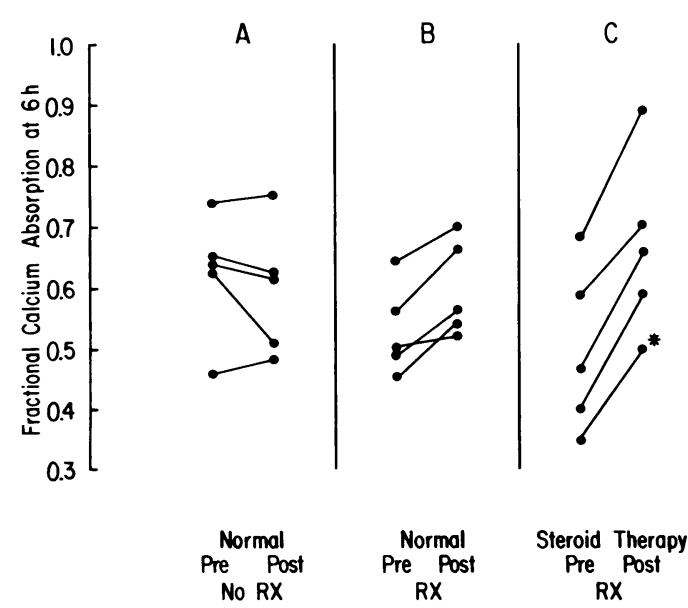

FIgURE 4 Fractional intestinal absorption of calcium before and after 7 days of no therapy or oral administration of $1,25(\mathrm{OH})_{2} \mathrm{D}_{3}$. (A) No therapy in normal volunteers; (B) 0.4 $\mu \mathrm{g}$ daily for 7 days to normal volunteers; (C) $0.4 \mu \mathrm{g}$ daily for 7 days to high-dose steroid patients. One patient $\left(^{*}\right)$ on high-dose steroid treatment represents the only patient in the study whose underlying collagen disease was clinically active. 
The cause of bone loss in corticosteroid-induced osteoporosis is undoubtedly complex. The several factors that many contribute to the bone disease include decreased collagen synthesis, decreased renal conservation of calcium, and intestinal calcium malabsorption (12). Our data document the relationship between steroid dose and abnormal vitamin $D$ metabolism and calcium malabsorption. Thus, they suggest that it may be possible to control the defect in calcium transport by specific therapy with synthetic metabolites of vitamin D. In this regard, it is of interest that Hahn et al. (37) have recently reported that therapy with moderately large doses of synthetic 25-OH-D increased intestinal calcium absorption and peripheral bone density in patients with exogenous hypercortisonism.

\section{ACKNOWLEDGMENTS}

We are indebted to Dr. Claude D. Arnaud, Head, Endocrine Research Unit, for helpful counsel during these studies as well as for provision of laboratory facilities for their performance. We also gratefully acknowledge the excellent technical assistance of the employees working in the Mineral Research Laboratory, especially Juliann Mary Meger; the help of the nursing staff of the Russell M. Wilder Clinical Study Unit, especially Mrs. Deanna L. Nash; the dietitians under the direction of Ms. Esperanza R. Briones; and the secretarial assistance provided by Ms. Janice A. Bohn and Ms. Charlene L. Lingk.

This investigation was supported in part by National Institutes of Health grants AM 8658, 12302, 18977, and RR 585 from the U. S. Public Health Service, and by a grant from the Minnesota Arthritis Foundation.

\section{REFERENCES}

1. Harrison, H. E., and H. C. Harrison. 1960. Transfer of $\mathrm{Ca}^{45}$ across intestinal wall in vitro in relation to action of vitamin D and cortisol. Am. J. Physiol. 199: 265-271.

2. Williams, G. A., E. N. Bowser, W. J. Henderson, and V. Uzgiries. 1961. Effects of vitamin D and cortisone on intestinal absorption of calcium in the rat. Proc. Soc. Exp. Biol. Med. 106: 664-666.

3. Kimberg, D. V., R. D. Baerg, E. Gershon, and R. T. Graudusius. 1971. Effect of cortisone treatment on the active transport of calcium by the small intestine. J. Clin. Invest. 50: 1309-1321.

4. Gallagher, J. C., J. Aaron, A. Horsman, R. Wilkinson, and B. E. C. Nordin. 1973. Corticosteroid osteoporosis. Clinics Endocrinol. Metab. 2: 355-368.

5. Favus, M. J., D. V. Kimberg, G. N. Millar, and E. Gershon. 1973. Effects of cortisone administration on the metabolism and localization of 25-hydroxycholecalciferol in the rat. J. Clin. Invest. 52: 1328-1335.

6. Favus, M. J., M. W. Walling, and D. V. Kimberg. 1973. Effects of 1,25-dihydroxycholecalciferol on intestinal calcium transport in cortisone-treated rats. J. Clin. Invest. 52: $1680-1685$.

7. Collins, E. J., E. R. Garrett, and R. L. Johnston. 1962. Effect of adrenal steroids on radio-calcium metabolism in dogs. Metab. Clin. Exp. 11: 716-726.
8. Lukert, B. P., S. W. Stanbury, and E. B. Mawer. 1973. Vitamin D and intestinal transport of calcium: effects of prednisolone. Endocrinology. 93: 718-722.

9. Wajchenberg, B. L., V. G. Pereira, J. Kieffer, and S. Ursic. 1969. Effect of dexamethasone on calcium metabolism and ${ }^{47} \mathrm{Ca}$ kinetics in normal subjects. Acta Endocrinol. 61: 173-192.

10. Teotia, M., S. P. S. Teotia, T. Raman, N. L. Sharma, and R. K. Singh. 1975. Intestinal absorption of calcium and phosphorus: experiments on interaction between vitamin $\mathrm{D}$ and adrenocortical hormone. Indian J. Pediatr. 42: 1-9.

11. Miravet, L., D. Hioco, N. Debeyre, A. Dryll, A. Ryckewaert, and S. de Sèze. 1966. La cinétique du calcium au cours de l'ostéoporose cortisonique. Effet d'un anabolisant de synthèse. Sem. Hop. Paris. 42(Suppl.): 60-64.

12. Rasmussen, H., and P. Bordier. 1974. The Physiological and Cellular Basis of Metabolic Bone Disease. Williams \& Wilkins Company, Baltimore. 364 pp.

13. DeLuca, H. F. 1976. Recent advances in our understanding of the vitamin $\mathrm{D}$ endocrine system. J. Lab. Clin. Med. 87: 7-26.

14. Avioli, L. V., S. J. Birge, and S. W. Lee. 1968. Effects of prednisone on vitamin $\mathrm{D}$ metabolism in man. J. Clin. Endocrinol. Metab. 28: 1341-1346.

15. Aloia, J. F., M. Roginsky, K. Ellis, K. Shukla, and S. Cohn. 1974. Skeletal metabolism and body composition in Cushing's syndrome.J. Clin. Endocrinol. Metab. 39: 981985.

16. Kimberg, D. V. 1969. Effects of vitamin D and steroid hormones on the active transport of calcium by the intestine. N. Engl. J. Med. 280: 1396-1405.

17. Carré, M., O. Ayigbedé, L. Miravet, and H. Rasmussen. 1974. The effect of prednisolone upon the metabolism and action of 25-hydroxy- and 1,25-dihydroxyvitamin $\mathrm{D}_{3}$. Proc. Natl. Acad. Sci. U. S. A. 71: 2996-3000.

18. Szymendera, J., R. P. Heaney, and P. D. Saville. 1972. Intestinal calcium absorption: concurrent use of oral and intravenous tracers and calculation by the inverse convolution method. J. Lab. Clin. Med. 79: 570-578.

19. Birge, S. J., W. A. Peck, M. Berman, and G. D. Whedon. 1969. Study of calcium absorption in man: a kinetic analysis and physiologic model. J. Clin. Invest. 48: 17051713.

20. Arnaud, S. B., G. B. Stickler, and J. C. Haworth. 1976. Serum 25-hydroxyvitamin D in infantile rickets. Pediatrics. 57: 221-225.

21. Haddad, J. G., and K. J. Chyu. 1971. Competitive protein-binding radioassay for 25-hydroxycholecalciferol. J. Clin. Endocrinol. Metab. 33: 992-995.

22. Bligh, E. G., and W. J. Dyer. 1959. A rapid method of total lipid extraction and purification. Can.J. Biochem. Physiol. 37: 911-917.

23. Holick, M. F., and H. F. DeLuca. 1971. A new chromatographic system for vitamin $\mathrm{D}_{3}$ and its metabolites: resolution of a new vitamin $\mathrm{D}_{3}$ metabolite. J. Lipid Res. 12: 460-465.

24. Arnaud, S. B., R. S. Goldsmith, P. W. Lambert, and V. L. W. Go. 1975. 25-Hydroxyvitamin $D_{3}$ : evidence of an enterohepatic circulation in man. Proc. Soc. Exp. Biol. Med. 149: 570-572.

25. Haddad, J. G., and T. C. B. Stamp. 1974. Circulating 25hydroxyvitamin D in man. Am. J. Med. 57: 57-62.

26. Norman, A. W., and H. Henry. 1974. The role of the kidney and vitamin $\mathrm{D}$ metabolism in health and disease. Clin. Orthop. 98: 258-287.

27. Brickman, A.S., J. W. Cobur, S. G. Massry, and A. W. Norman. 1974. 1,25 Dihydroxy-vitamin $D_{3}$ in normal man 
and patients with renal failure. Ann. Intern. Med. 80: 161168.

28. Balsan, S., M. Garabedian, R. Sorgniard, M. F. Holick, and H. F. DeLuca. 1975. 1,25-Dihydroxyvitamin $D_{3}$ and $1, \alpha$-hydroxyvitamin $D_{3}$ in children: biologic and therapeutic effects in nutritional rickets and different types of vitamin D resistance. Pediatr. Res. 9: 586-593.

29. Jee, W. S. S., W. E. Roberts, H. Z. Park, G. Julian, and M. Kramer. 1972. Interrelated effects of glucocorticoid and parathyroid hormone upon bone remodeling. Excerpta Med. Int. Congr. Ser. 243: 430-439.

30. Stamp, T. C. B., J. M. Round, D. J. F. Rowe, and J. G. Haddad. 1972. Plasma levels and therapeutic effect of 25-hydroxycholecalciferol in epileptic patients taking anticonvulsant drugs. Br. Med. J. 4: 9-12.

31. Hahn, T. J., S. J. Birge, C. R. Scharp, and L. V. Avioli. 1972. Phenobarbital-induced alterations in vitamin D metabolism. J. Clin. Invest. 51: 741-748.

32. Conney, A. H. 1967. Pharmacological implications of microsomal enzyme induction. Pharmacol. Rev. 19: 317366.
33. Gelehrter, T. D. 1976. Enzyme induction (Second of three parts.) N. Engl. J. Med. 294: 589-595.

34. Miravet, L., M. Carré, O. Ayigbedé, and H. Rasmussen. 1975. The effect of prednisolone upon intestinal metabolism and action of 25-hydroxy and 1,25-dihydroxyvitamin $\mathrm{D}_{3}$. In Vitamin D and Problems Related to Uremic Bone Disease. A. W. Norman, K. Schaefer, H.-G. Grigoleit, D. von Herrath, and E. Ritz, editors. Walter de Gruyter and Co., Berlin. 59-65.

35. Coburn, J. W., M. H. Koppel, A. S. Brickman, and S. G. Massry. 1973. Study of intestinal absorption of calcium in patients with renal failure. Kidney Int. 3: 264-272.

36. Melby, J. C. 1974. Systemic corticosteroid therapy: pharmacology and endocrinologic considerations. Ann. Intern. Med. 81: 505-512.

37. Hahn, T. J., L. R. Halstead, C. R. Scharp, and B. H. Hahn. 1976. Mineral metabolism and response to 25-hydroxyvitamin $D$ therapy in patients with steroid induced osteopenia. Program of the Meeting of the Endocrine Society. 58: 62. (Abstr.) 